\title{
EDUKASI DAN PENDAMPINGAN PENGOLAHAN SAMPAH BERBASIS 3R (REDUCE, REUSE, RECYCLE) PADA SANTRI DI PESANTREN SABILUNNAJAT, CIAMIS
}

\section{R (REDUCE, REUSE, RECYCLE) WASTE PROCESSING EDUCATION AND FACILITIES IN SANTRI IN SABILUNNAJAT PESANTREN, CIAMIS}

\author{
${ }^{1)}$ Ernyasih ${ }^{*},{ }^{2}$ Fini Fajrini, ${ }^{3}$ Leandra Binar Elyasa, ${ }^{4)}$ Qodimah Alfiana \\ 1,2,3,4) Jurusan Kesehatan Masyarakat, Universitas Muhammadiyah Jakarta \\ Alamat: Jl. K.H. Ahmad Dahlan, Cireundeu, Ciputat \\ "Email : ummi.rifali@gmail.com
}

\begin{abstract}
ABSTRAK
Semakin meningkatnya jumlah sampah maka diperlukan pengolahan sampah yang benar. Sesuai dengan Peraturan Pemerintah Republik Indonesia Nomor 81 Tahun 2012 tentang Pengelolaan Sampah Rumah Tangga dan Sampah Sejenis Rumah Tangga. Santri di pondok pesantren Sabilunnajat belum memiliki pengetahuan mengenai pengelolaan sampah berbasis reduce, reuse, recycle. Maka dari itu kami pengadakan edukasi pengolahan sampah yang diasistensi oleh mahasiswa jurusan kesehatan masyarakat fakultas kesehatan masyarakat universitas muhammadiyah Jakarta. Tujuannya adalah meningkatkan pengetahuan santri mengenai pengolahan sampah dan dapat menerapkannya dilingkungan pesantren. Metode yang digunakan dalam kegiatan ini adalah penyuluhan dan pendampingan mengenai pengolahan sampah. Hal ini mendapat respon yang baik dan positif dari guru dan santri karena sangat berguna bagi santri agar mengetahui tentang pengolahan sampah yang benar dan mempraktikan dalam lingkungan pesantren.
\end{abstract}

Kata kunci: Pengolahan sampah, edukasi, santri.

\begin{abstract}
Increasing the amount of waste requires correct waste management. In accordance with Government Regulation of the Republic of Indonesia Number 81 Year 2012 concerning Management of Household Waste and Similar Household Waste. Islamic Student in Sabilunnajat boarding school do not have knowledge about waste management based on reduce, reuse, recycle. Therefore, we organize waste management education which is assisted by students majoring in public health, Faculty of Public Health, Muhammadiyah University, Jakarta. The aim is to increase students' knowledge about waste management and be able to apply it to the pesantren environment. The method used in this activity is counseling and assistance regarding waste management. This gets a good and positive response from teachers and students because it is very useful for students to know about correct waste management and practice in the pesantren environment
\end{abstract}

Keyword: management waste, education, Islamic students 
AS-SYIFA: Jurnal Pengabdian dan Pemberdayaan Kesehatan Masyarakat

\section{PENDAHULUAN}

Sampah merupakan istilah umum yang sering digunakan sebagai limbah padat. Limbah adalah sesuatu yang tidak digunakan, tidak terpakai, tidak disenangi atau sesuatu yang dibuang dan berasal dari kegiatan manusia serta tidak terjadi dengan sendirinya. Sampah dapat dipengaruhi oleh jumlah penduduk, karena semakin banyak penduduk, maka jumlah sampah akan semakin banyak pula (Sumantri, 2010).

Sampah yang tidak dikelola dengan baik dapat mengakibatkan sampah menjadi tempat perkembangbiakan vector penyakit, seperti lalat dan tikus sehingga dapat menimbulkan penyakit seperti diare dan demam berdarah ataupun terjadinya kecelakaan misalnya luka yang disebabkan oleh benda tajam seperti kaca ataupun paku. Selain itu pembuangan sampah yang tidak benar dapat menimbulkan pencemaran lingkungan. Ada berbagai hal yang dapat menjadikan sampah sulit utuk dikelola dengan baik, antara lain yaitu pesatnya perkembangan teknologi, meningkatnya tingkat hidup masyarakat, yang tidak disertai dengan pengetahuan tentang sampah, meningkatnya biaya operasi, pengelolaan sampah, kebiasaan pengelolaan sampah yang tidak benar, semakin sulitnya mendapatkan lahan sebagai tempat pembuangan akhir (TPA) sampah dan sulitnya mencari partisipasi masyarakat untuk membuang sampah pada tempatnya serta memelihara kebersihan. (Chandra, 2012)

Berdasarkan zat kimia yang terkandung didalamnya, sampah dapat dibedakan menjadi sampah organik dan anorganik. Sampah organik merupakan sampah yang dapat diurai oleh mikroorganisme atau yang dapat membusuk seperti sampah sisa makanan, daun, sayur dan buah. Sedangkan sampah anorganik merupakan sampah yang membutuhkan waktu yang sangat lama untuk terurai, bahkan cenderung sukar terurai oleh mikroorganisme, misalnya plastik, kaca dan keleng. (Sumatri, 2010).

Menurut ScienceMag, jumlah produksi sampah plastik global sejak 1950 sampai 2015 cenderung meningkat. Pada tahun 1950, produksi sampah dunia mencapai 2ton pertahun, namun pada tahun 2015 mengalami peningkatan produksi sampah yaitu 381 juta ton pertahun. NASA merilis animasi yang menunjukkan kondisi sampah di lautan dunia. Sampah menumpuk di lima bagian samudra terbesar di Bumi. Wold Economic Forum (WEF) memprediksi pada tahun 2050, jumlah plastik dilautan akan lebih banyak. Sedangkan pada tahun 2019, di Indonesia sampah mencapai 68 juta ton. Sampah yang masih mendominasi di Indonesia adalah sampah organik sebesar $75 \%$, dilanjutkan dengan sampah plastik $13 \%$, sampah dari logam $5 \%$, sampah kertas 3\%, sampah kaca 3\% dan sampah dari kayu $1 \%$. (Kementrian Pekerjaan Umum, 2010)

Melihat fenomena yang menunjukkan semakin meningkatnya jumlah sampah maka diperlukan pengolahan sampah yang benar. Sesuai dengan Peraturan Pemerintah Republik Indonesia Nomor 81 Tahun 2012 tentang Pengelolaan Sampah Rumah Tangga dan Sampah Sejenis Rumah Tangga, Pasal 1 menyatakan bahwa pengelolaan sampah adalah kegiatan yang sistematis, menyeluruh dan berkesinambungan yang meliputi pengurangan dan penanganan sampah. Pengelolaan tersebut dapat dilakukan dengan pendekatan $3 \mathrm{R}$ (Reduce, Reuse, Reycle). Reduce (mengurangi) artinya upaya yng lebih menitikberatkan pada pengurangan pola hidup komsumtif serta senantiasa mengguakan "tidak sekali pakai" yang ramah lingkungan dan mencegah timbulan sampah. Reuse (menggunakan kembali) artinya upaya memanfaatkan bahan sampah melalui penggunaan yang berulang agar tidak langsn menjadi sampah, tanpa pengolahan berarti menggunakan kembali sampah yang ayak pakai unuk fungsi yang sama atau yang lain. Sadangkan Recycle (mendaur ulang sampah) artinya setelah sampah harus keluar dari lingkungan rumah perlu dilakukan pemilahan dan pemanfaatan dari lingkungan rumah perlu dilakukan pemilahan dan pengolahan secara setempat menjdi produk baru. (Kementrian Pekerjaan Umum, 2010) 
Pondok pesantren merupakan lembaga pendidikan keagamaan yang tidak dapat dilepaskan dari masyarakat dimana pondok pesantren tersebut tumbuh dan berkembang. Sejarah menunjukkan bahwa pada umumnya pesantren berada di wilayah pedesaan atau menyatu dengan kehidupan masyarakat desa. Kehidupan pondok pesantren sangat beragam, karena dibentuk oleh situasi social dan budaya serta lingkungan fisik yang berbeda. (Ali, 2005)

Pondok pesantren merupakan istilah yang berasal dari dua kata, yaitu "pondok" dan "pesantren". Penyatuan dua istilah ini mengandung arti yaitu tempat belajar para santri. (Malik, 2005). Pondok Pesantren merupakan salah satu pendidikan Islam yang sering identik dengan kurangnya manajemen lingkungan didalamnya, terutama pengelolaan sampahya. (Auvaria, 2016). Menurut Fahham (2019) menyatakan bahwa masih banyak pesantren yang belum memiliki pengelolaan sampah.

Pondok pesantren Sabilunnajat berada di Cileungsir, Rancah di Kabupaten Ciamis dengan jumlah santri 300 orang dari berbagai daerah. Dengan banyaknya jumlah santri menyebabkan semakin banyak sampah di lingkungan pesantren. Banyak santri yang membuang sampah sembarangan karena kurangnya pengetahuan dan kesadaran mengenai sampah. Selain itu cara pengolahan sampah dipesantren belum baik, Sampah hanya dikumpulkan di satu tempat lalu dibakar. Pembakaran dapat menyebabkan pencemaran udara dan akan berdampak pada lingkungan sekitar pesantren.

Berdasarkan analisis situasi di pesantren Sabilunnajat, maka diperlukan edukasi mengenai pengolahan sampah yang benar dengan pendekatan $3 \mathrm{R}$ dan dapat menerapkannya dilingkungan pesantren.

\section{METODE}

Kegiatan pengabdian masyarakat dilaksanakan pada tanggal 23 Februari 2020 di Pondok Pesantren Sabilunnajat di Cileungsir, Rancah di Kabupaten Ciamis. Metode yang digunakan dalam kegiatan ini dibagi menjadi dua tahap. Tahap pertama yaitu tim pengabdian melakukan penyuluhan mengenai pengolahan sampah berbasis 3R. Kemudian tahap kedua yaitu mendampingi santri praktek pengolahan sampah 3R berbasis 3R. Bahan yang disiapkan adalah sampah kertas yang akan digunakan kembali.

\section{HASIL DAN PEMBAHASAN}

Kegiatan pengabdian masyarakat dibagi menjadi dua tahap, antara lain :

a) Tahap Pertama : penyuluhan mengenai pengolahan sampah berbasis $3 \mathrm{R}$

Pengetahuan adalah kesan dimana dalam pikiran manusia sebagai hasil dalam penggunaan pancaindera, dan berbeda dengan kepercayaan, takhayul, maupun penerapan-penerapan yang keliru. (Soekanto, 2003).Pengetahuan membentuk sikap seseorang untuk melakukan tindakan atau perilaku. Dengan diberikannya penyuluhan tentang pengolahan sampah berbasis $3 \mathrm{R}$ bertujuan untuk meningkatkan pengetahuan santri mengenai pengolahan sampah sehingga menimbulkan kesadaran santri untuk melakukan pengolahan sampah yang benar dengan pendekatan 3R. Penyuluhan dilaksanakan berbeda antara santri perempuan dan laki-laki. 


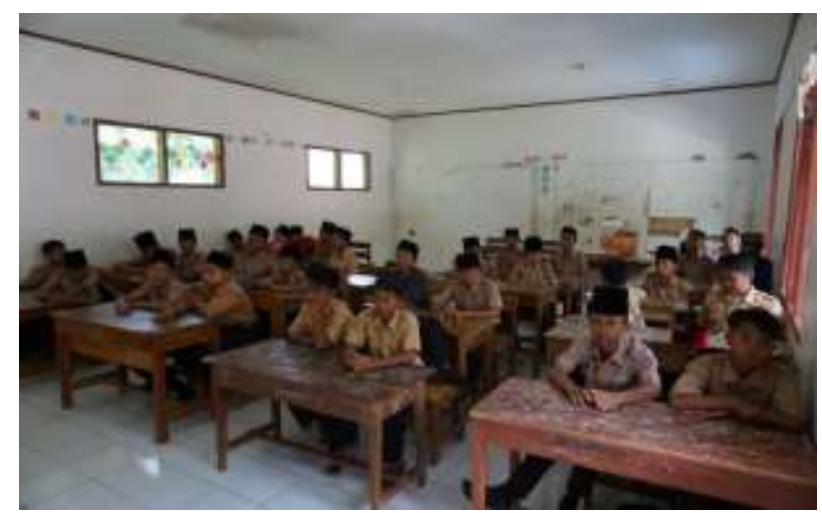

Sumber : Dokumentasi primer, 2020

Gambar 1. Penyuluhan terhadap santri laki-laki

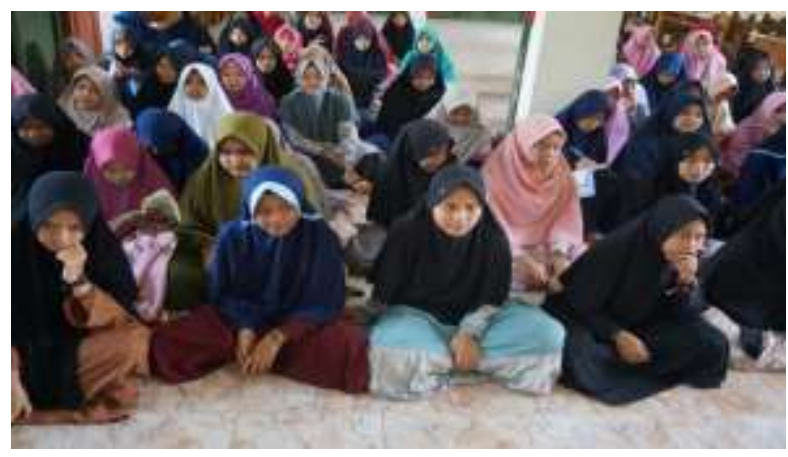

Sumber : Dokumentasi primer, 2020

Gambar 2. Penyuluhan terhadap santri perempuan

Penyuluhan pengolahan sampah berbasis 3R dimulai dengan pertanyaanpertanyaan mengenai sampah dan lingkungan sekitar. Kemudian santri diberikan materi mengenai sampah dan dampak buruk yang terjadi bila sampah tidak diolah dengan benar setelah itu baru dijelaskan mengenai pengolahan sampah berbasis $3 \mathrm{R}$. Santri sangat antusias, hal ini terlihat banyak santri yang bertanya.

Penyuluhan tersebut akan meningkatkan pengetahuan santri, hal ini sesuai dengan Notoatmodjo (2007) yang mengungkapkan bahwa pengetahuan atau kognitif merupakan domain yang sangat penting untuk terbentuknya tindakan seseorang.

b) Tahap Kedua : Mendampingi santri melakukan praktek pegolahan berbasis $3 \mathrm{R}$

Setelah diberikan penyuluhan, santri melakukan praktek pengolahan sampah berbasis $3 \mathrm{R}$ didampingi tim pengabdian masyarakat. 
AS-SYIFA: Jurnal Pengabdian dan Pemberdayaan Kesehatan Masyarakat

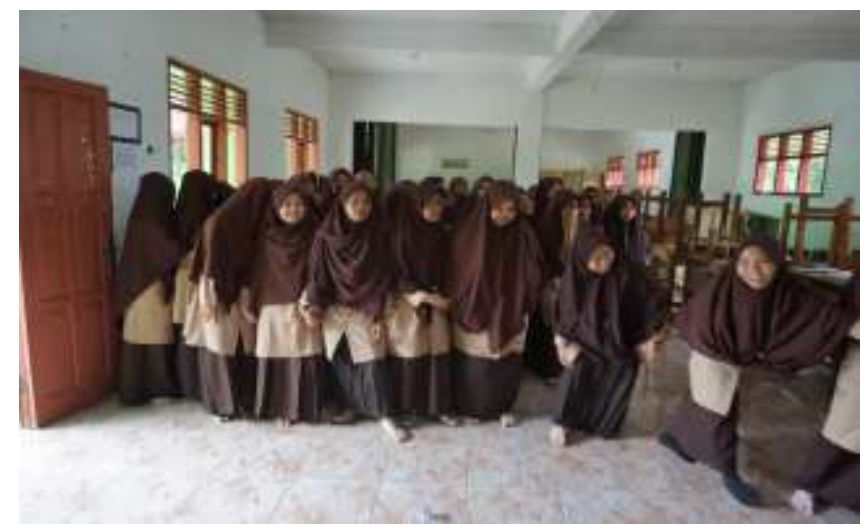

Sumber : Dokumentasi primer, 2020

Gambar 3. Bersiap praktek

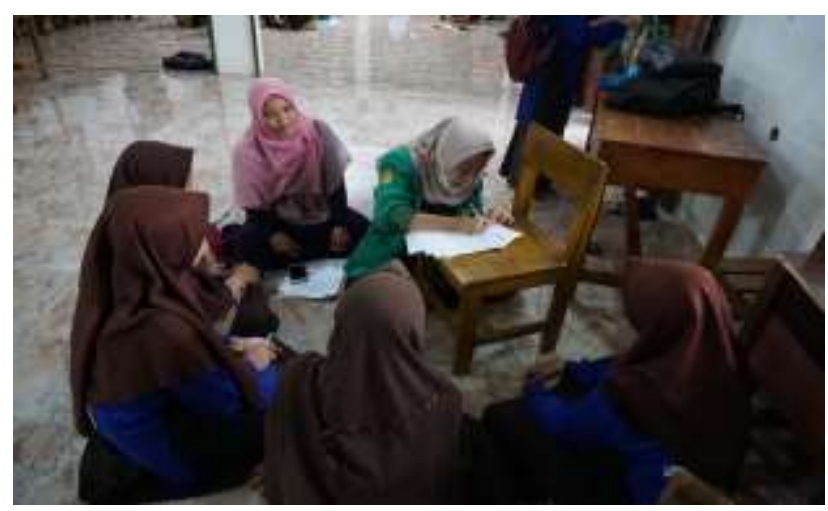

Sumber: Dokumentasi primer, 2020

Gambar 4. praktek pengolahan sampah berbasis $3 \mathrm{R}$

Langkah yang dilakukan adalah bermain peran dalam melakukan pengolahan sampah berbasis $3 R$.

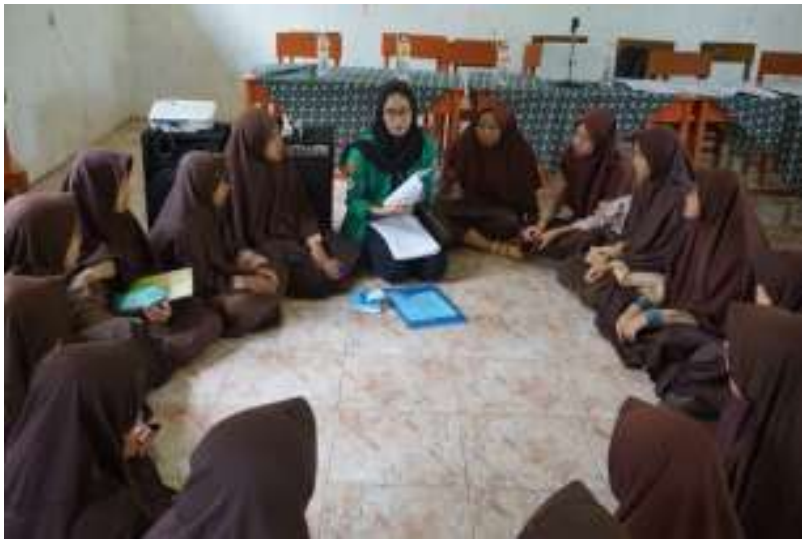

Sumber : Dokumentasi primer, 2020

Gambar 5. Praktek pengolahan sampah berbasis 3R 


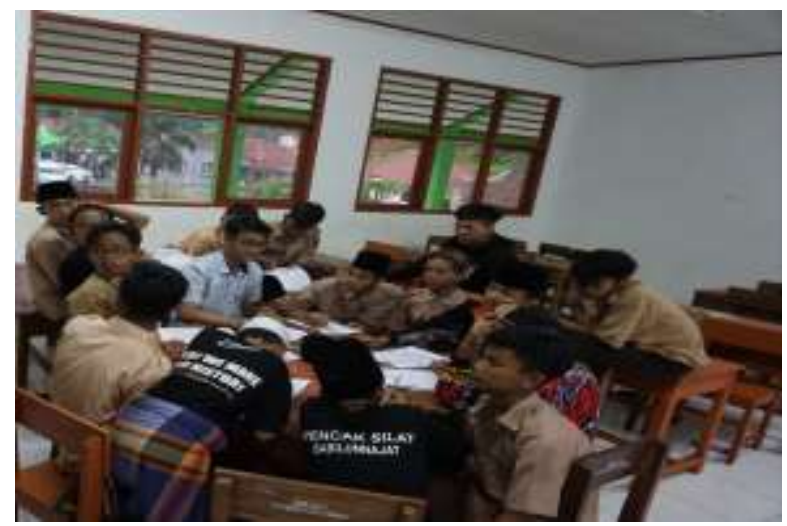

Sumber: Dokumentasi primer, 2020

Gambar 6. Praktek pengolahan sampah berbasis 3R

Pemberiam penyuluhan diharapkan akan merubah sikap yang baik sehingg menimbulkan perilaku yang baik pula. Hal ini sesuai dengan penyataan Elizabeth (2017), menyatakan bahwa santri mulai menyadari arti pengelolaan sampah yang benar setelah diberikan penyuluhan, karena bila tidak dilakukan dengan benar, maka akan menimbulkan pencemaran untuk lingkungan sekitar pesantren.

\section{KESIMPULAN DAN SARAN}

Kegiatan yang dilakukan oleh mahasiswa dan dosen sebagai tim pengabdian masyarakat Fakultas Kesehatan Masyarakat Universitas Muhammadiyah Jakarta mendapatkan respon yang baik dari pihak santri. hal ini dapat terlihat dari penerimaan dan hadirnya santri dalam penyuluhan dan praktek pengolahan sampah berbasis 3R. Selain itu, pihak pesantren merasa terbantu dengan adanya penyuluhan ini, karena dengan kegiatan ini dapat merubah perilaku santri dalam pengelolaan sampah berbasis 3R. Diharapkan dengan adanya kegiatan pengabdian masyarakat, santri dapat terus melakukan pengolahan sampah 3R secara konsisten.

\section{UCAPAN TERIMA KASIH}

Ucapan terima kasih kepada UPT penelitian dan pengabdian masyarakat Fakultas Kesehatan Masyarakat, Pengurus Pondok Pesantren Sabilunnajat. Program pengabdian masyarakat yang dilaksanakan mendapat respon yang baik dari pesantren.

\section{DAFTAR PUSTAKA}

Ali Aziz, Muh. 2005. Dakwah Pemberdayaan Masyarakat Paradigma AKsi Metodologi. Yogyakarta; Pustaka Pesantren

Auvaria, Wazna Shinfi. 2016. Perencanaan Pengelolaan Sampah di Pondok Pesantren Langitan Kecamatan Widang Tuban. Al-Ard. Jurnal Teknik Lingkungan. Volume 2. Nomor 1

Chandra, Budiman. 2012. Pengantar Kesehatan Lingkungan. Penerbit buku Kedokteran. EGC

Elizabeth, Misbah Zulfa. 2017. Program Pengelolaan Kebersihan Lingkungan di Pesantren. DIMAS. Volume 17 Nomor 1

Fahham, Achmad Muchaddam. 2019. Sanitasi dan Dampaka Bagi Kesehatan: Studi Dari Pesantren. Aspirasi: Jurnal Masalah-masalah sosal. Volume 10. No 1 Juni 2019

Kementrian Pekerjaan Umum. 2010. Modul Sampah Berbsis 3R

Malik, Jamaluddin. 2005. Pemberdayaan Pesantren. Yogyakarta: Pustaka Pesantren 
Volume. 1 No. 1. Hal. $16-22$

Mei 2020-November 2020
ISSN (online): 2722-2055 https://jurnal.umj.ac.id/index.php/AS-SYIFA
AS-SYIFA: Jurnal Pengabdian dan Pemberdayaan Kesehatan Masyarakat

Notoatmodjo, S. 2007. Kesehatan Masyarakat (Ilmu dan Seni). Rineka Cipta. Jakarta

Peraturan Pemerintah Republik Indonesia Nomor 81 Tahun 2012 tentang Pengelolaan Sampah Rumah Tangga dan Sampah Sejenis Rumah Tangga

Sumantri, Arif. 2010. Kesehatan Lingkungan Edisi Ketiga. Kencana Prenada Media Group Soekanto, S. 2003. Sosiologi Suatu Pengantar., CV Rajawali. Jakarta 